\title{
Gene Transfer in Acinetobacter calcoaceticus: Fertility Variants of the Sex Factor pAV1
}

\author{
By EDWARD HINCHLIFFE* AND ALAN VIVIAN \\ School of Biological Sciences, Thames Polytechnic, London SE18 6PF
}

(Received 14 December 1979; revised 21 January 1980)

\begin{abstract}
The naturally occurring transmissible plasmid pAV1 mediates chromosome transfer and can exhibit two distinct levels of transmissibility in Acinetobacter calcoaceticus strain EBF65/65. The two states of pAV1 have been arbitrarily designated pAV1a (low frequency variant) and $\mathrm{pAV} 1 \mathrm{~b}$ (high frequency variant). Both variants have the same incompatibility and host range properties and each mobilizes two non-transmissible resistance determinants for tetracycline and neomycin. Sex factor activity has been shown to be stable: however, pAV1b fertility variants can be derived from pAV1a donors following conjugal transfer of pAV1 into new recipient strains of EBF65/65.
\end{abstract}

\section{INTRODUCTION}

Acinetobacter calcoaceticus strain EBF65/65 has been investigated genetically by Towner \& Vivian $(1976 a, b)$ using the P class R plasmid RP4 to promote chromosome transfer. A circular linkage map was obtained by Towner (1978) which orders 23 genes. More recently, Hinchliffe \& Vivian (1980) reported the discovery of a naturally occurring plasmid in a hospital strain of $A$. calcoaceticus which could be transferred to strain EBF65/65. The plasmid, designated pAV1, was transmissible within strains of EBF65/65 and mediated resistance to sulphonamides. It was incompatible with $\mathrm{P}$ class plasmids in tests performed in A. calcoaceticus.

In this paper we report the discovery that pAV1 can mediate chromosome transfer, and also that it can exhibit two distinct levels of transmissibility within EBF65/65.

\section{METHODS}

Acinetobacter strains and plasmids. These are listed in Table 1 together with their sources.

Media. Minimal medium (MM), Tryptone Soya Agar (TSA) (Towner \& Vivian, 1976a) and basal salts medium (BSM) (Towner, 1978) were used.

Antibiotics. These were obtained from Sigma (except where indicated) and were added to media as freshly prepared solutions at the following final concentrations: sulphadiazine, $500 \mu \mathrm{g} \mathrm{ml}^{-1}$; rifampicin, $100 \mu \mathrm{g}$ $\mathrm{ml}^{-1}$; tetracycline hydrochloride, $5 \mu \mathrm{g} \mathrm{ml}^{-1}$; neomycin sulphate, $50 \mu \mathrm{g} \mathrm{ml}^{-1}$; trimethoprim lactate (Wellcome), $500 \mu \mathrm{g} \mathrm{ml}^{-1}$.

Millipore mating technique. The method of Towner \& Vivian (1976 b) was used for all quantitative crosses. Replica plate mating. This was as described by Hinchliffe \& Vivian (1980).

Selection for $R$ plasmid transfer. Selection for transfer between strain JC17 and strain C4121 was made by the method of Hinchliffe \& Vivian (1980).

Stability of plasmids. This was determined as described by Towner \& Vivian (1976 b). 


\section{Table 1. Strains of Acinetobacter calcoaceticus and plasmids}

\begin{tabular}{ll}
$\begin{array}{l}\text { Strain } \\
\text { Bacteria }\end{array}$ & \multicolumn{1}{c}{ Relevant characteristics } \\
JC17 & Intrinsic high level resistance to kanamycin and ampicillin \\
& TC* NM* (pAV1) \\
EBF65/65 & Intrinsic high level resistance to kanamycin and ampicillin \\
C48 & met-1 ile-1 \\
C426 & trp-2 his-1 \\
C459 & cys-3 ala-1 \\
C476 & ura-1 arg-10 trp-2 his-1 \\
C484 & phe-1 thi-2 \\
C4121 & trp-2 his-1 rif-1 \\
C4131 & phe-1 thi-2 (R751) \\
C4141 & trp-2 his-1 rif-1 TC* NM* (pAV1a) \\
C4145 & trp-2 his-1 rif-1 TC* NM* (pAV1b) \\
C4151 & trp-2 his-1 (pAV1b) \\
C4152 & met-1 ile-1 (pAV1b) \\
C4153 & met-1 ile-1 (pAV1a) \\
C4156 & trp-2 his-1 (RP4) \\
Plasmids $\dagger$ & \\
pAV1 & Su \\
RP4 & Tc Km Ap \\
R751 & Tp
\end{tabular}

Reference/source

Hinchliffe \& Vivian (1980)

Towner \& Vivian (1976a)

Auxotroph of EBF65/65

Auxotroph of EBF65/65

Auxotroph of EBF65/65

Auxotroph of EBF65/65

Auxotroph of EBF65/65

Auxotroph of EBF65/65

E. coli $\mathrm{J} 62(\mathrm{R} 751) \times \mathrm{C} 484$

$\mathrm{JC17} \times \mathrm{C} 4121$

$\mathrm{JC} 17 \times \mathrm{C} 4121$

$\mathrm{C} 4152 \times \mathbf{C 4 2 6}$

$\mathrm{C} 4145 \times \mathrm{C} 48$

$\mathrm{C} 4141 \times \mathrm{C} 48$

E. coli J53(RP4) $\times \mathrm{C} 426$

Hinchliffe \& Vivian (1980)

Datta et al. (1971)

Jobanputra \& Datta (1974)

* Probably plasmid-borne tetracycline and neomycin resistances.

$\dagger$ Abbreviations (resistance to): Ap, ampicillin; Km, kanamycin; Su, sulphonamides; Tc, tetracycline; $\mathrm{Tp}$, trimethoprim.

\section{RESULTS}

pAV1+ strains of EBF65/65 exhibit two levels of transmissibility

Hinchliffe \& Vivian (1980) described the transfer and isolation of pAV1+ transconjugants from a Millipore mating between the hospital strain JC17 and strain C4121, a derivative of EBF65/65. A sample of these transconjugants was subsequently tested by replica plate mating with strain $\mathrm{C} 48$. Selection was made for transfer of sulphonamide resistance. Eleven original transconjugants were tested in this way: nine of them showed transfer of sulphonamide resistance to strain $\mathrm{C} 48$ with a high frequency, whereas two showed a markedly lower frequency of transfer. The two types of donor strain could be easily distinguished by the replica plate mating method. Subsequent Millipore crosses between strains of EBF65/65 showed that low frequency fertility variants transferred sulphonamide resistance at a frequency of $4 \times 10^{-6} R^{+}$transconjugants per recipient, compared with a frequency of $2 \times 10^{-1}$ for high frequency fertility variants.

For convenience these two types of $\mathrm{pAV1}^{+}$strain have been designated pAV1a for the strain showing low level transfer and pAV1b for the strain showing high level transfer of sulphonamide resistance. It is also convenient to designate the levels of transfer as either a-type or b-type for low and high level transfer, respectively.

It is now clear that the characteristics described for pAV1 by Hinchliffe \& Vivian (1980) relate to pAV1b strains.

\section{Characteristics of pAV1a strains}

pAV1a strains resemble pAV1b strains as described by Hinchliffe \& Vivian (1980) with respect to host range. The potential hosts included strains of Klebsiella, Proteus mirabilis, Pseudomonas aeruginosa and Escherichia coli previously tested with pAV1b strains. The stability of pAV1a in strain C4153 was also similar to that previously described for pAV1b in strain C4145. Only two colonies in a sample of 975 colonies tested had lost sulphonamide resistance; the remaining 973 colonies were all of the pAV1a type with respect to their ability to transfer sulphonamide resistance to strain $\mathrm{C} 426$ by replica plate mating. In this way we have never detected a spontaneous change of pAV1 type: pAV1a strains remain a-type and pAV1b strains remain b-type. 
Table 2. Incompatibility properties of pAV1a

\begin{tabular}{|c|c|c|c|c|}
\hline Donor & Recipient & $\begin{array}{l}\text { Selected plasmid } \\
\text { resistance* }\end{array}$ & $\begin{array}{c}\text { Frequency of } \\
\text { R plasmid } \\
\text { transfert }\end{array}$ & $\begin{array}{l}\text { Characteristics of } \\
\text { transconjugants* }\end{array}$ \\
\hline C4153(pAV1a) & C4156(RP4) & $\mathrm{Su}$ & $9 \times 10^{-7}$ & NT \\
\hline C4156(RP4) & C4153(pAV1a) & $\mathrm{Tc}$ & $1.5 \times 10^{-4}$ & $\begin{array}{c}323(323) \mathrm{Tc}^{\mathrm{R}} \mathrm{Su}^{\mathrm{R}} \\
\text { (pAV1 retained) }\end{array}$ \\
\hline C4153(pAV1a) & C4131(R751) & $\mathrm{Su}$ & $1.5 \times 10^{-2}$ & $\begin{array}{l}0(46) \mathrm{Tp}^{\mathrm{R}} \mathrm{Su}^{\mathrm{R}} \\
\text { (R751 eliminated) }\end{array}$ \\
\hline C4131(R751) & C4153(pAV1a) & $\mathrm{Tp}$ & $3 \times 10^{-3}$ & $\begin{array}{l}51(51) \mathrm{Tp}^{\mathrm{R}} \mathrm{Su}^{\mathrm{R}} \\
\text { (pAV1 retained) }\end{array}$ \\
\hline
\end{tabular}

Stability of $R$ plasmids in pairs

\begin{tabular}{|c|c|c|c|c|c|}
\hline \multirow[b]{2}{*}{ Strain } & \multirow[b]{2}{*}{$\begin{array}{l}\text { Resistance } \\
\text { markers* }\end{array}$} & \multirow[b]{2}{*}{$\begin{array}{l}\text { No. of colonies } \\
\text { tested }\end{array}$} & \multicolumn{2}{|c|}{$\begin{array}{l}\text { No. of colonies } \\
\text { resistant to*: }\end{array}$} & \multirow{2}{*}{$\begin{array}{l}\text { No. of colonies } \\
\text { sensitive to } \\
\text { all antibiotics }\end{array}$} \\
\hline & & & $\mathrm{Su}$ & $\mathrm{Su} / \mathrm{Tc}$ & \\
\hline C4153(pAV1a)(RP4) & $\mathrm{Su}, \mathrm{Tc}$ & 982 & 955 & 21 & $\begin{array}{l}6 \\
4\end{array}$ \\
\hline C4153(pAV1a)(R751) & $\mathrm{Su}, \mathrm{Tp}$ & 807 & 803 & - & 4 \\
\hline
\end{tabular}

NT, Not tested.

* Su, sulphonamides; Tc, tetracycline; $\mathrm{Tp}$, trimethoprim.

$+\mathbf{R}^{+}$transconjugants per recipient.

$\ddagger$ Numbers in parenthesis indicate total number of colonies tested.

pAV1a strains also show similar incompatibility properties to pAV1b strains, since both variants are incompatible with the P class plasmids RP4 and R751 (Table 2). It should be noted that the presence of $R 751$ in the recipient strain C4131 resulted in a dramatic increase in the frequency of pAV1a transfer; such an increase was not observed in the same cross involving pAV1b.

\section{Mobilization of resistance determinants by $\mathrm{pAV} 1$}

Strain $\mathrm{JC17}$, as well as providing the transmissible plasmid pAV1, also harbours two non-transmissible resistance determinants for neomycin- and tetracycline-resistance which were mobilized by pAV1b strains (Hinchliffe \& Vivian, 1980). Further investigation has shown that pAVla strains also mobilize these determinants, but at a reduced frequency when compared with pAV1b strains (Table 3). Although there was variation between the frequencies from one cross to another, clearly pAVlb mobilization of both resistances was at a higher frequency than that of pAVla strains. Further, within individual crosses involving pAVla strains neomycin-resistance was invariably transferred at a slightly higher frequency than tetracycline-resistance. However, in crosses involving pAV1b strains no significant difference was observed.

\section{Chromosome mobilization by pAV1}

Both types of $\mathrm{pAV}^{+}$strain were capable of chromosome mobilization in $A$. calcoaceticus strain EBF65/65. However, the frequency of transfer of markers differed widely between the two types of pAV1+ strain (Table 4). The frequency of recombinants obtained by pAV1a mobilization of the chromosome was very low and did not enable any conclusions to be drawn about the nature of a-type mobilization. In contrast, pAV1b was very efficient as a sex factor and gave gene transfer frequencies for markers which were often 100 -fold or more higher than those obtained using RP4 (Towner \& Vivian, 1976a). Table 5 shows the relative frequencies obtained for different genetic markers spanning all regions of the chromosome according to the chromosomal map of Towner (1978). The data are insufficient to draw conclusions on the nature of chromosome mobilization: they serve to illustrate the relatively high frequencies of transfer obtained for markers in all regions of the genome. 
Table 3. Mobilization of resistance determinants by pAV1

$\begin{array}{cccc}\begin{array}{c}\text { Donor } \\ \text { C4141(pAV1a) }\end{array} & \text { Recipient } & \begin{array}{c}\text { Resistance selected } \\ \text { in recipient* }\end{array} & \begin{array}{c}\text { Frequency of transfer } \\ \left(10^{2} \times \mathrm{R}^{+} \text {transconjugants }\right. \\ \text { per recipient }\end{array} \\ & \mathrm{C} 48 & \mathrm{Tc} & 0 \cdot 45 \\ \text { C4141(pAV1a) } & \mathrm{C} 48 & \mathrm{Nm} & 1 \cdot 6 \\ & & \mathrm{Tc} & 1 \cdot 6 \\ \text { C4141(pAV1a) } & \mathrm{C} 484 & \mathrm{Nm} & 2 \cdot 6 \\ & & \mathrm{Tc} & 0 \cdot 06 \\ \text { C4145(pAV1b) } & \mathrm{C} 48 & \mathrm{Nm} & 0 \cdot 18 \\ & & \mathrm{Tc} & 9 \cdot 0 \\ \text { C4145(pAV1b) } & \mathrm{C} 48 & \mathrm{Nm} & 6 \cdot 4 \\ & & \mathrm{Tc} & 3 \cdot 8 \\ \text { C4145(pAV1b) } & \mathrm{C} 484 & \mathrm{Nm} & 3 \cdot 2 \\ & & \mathrm{Tc} & 8 \cdot 7 \\ & & \mathrm{Nm} & 9 \cdot 9\end{array}$

* Tc, tetracycline; $\mathrm{Nm}$, neomycin.

Table 4. Chromosome mobilization by fertility variants ' $a$ ' and ' $b$ '

\begin{tabular}{|c|c|c|c|}
\hline Donor & Recipient & $\begin{array}{l}\text { Selected donor } \\
\text { marker }\end{array}$ & $\begin{array}{l}\text { Average no. of recombinants } \\
\text { per } 10^{8} \text { recipient cells* }\end{array}$ \\
\hline C4141(pAV1a) & $\mathrm{C} 48$ & $\begin{array}{l}{\text { ile- } 1^{+}}^{\text {met }-1^{+}}\end{array}$ & $\begin{array}{l}7 \\
1\end{array}$ \\
\hline C4145(pAV1b) & C48 & $\begin{array}{l}\text { ile-1+ }^{+} \\
\text {met-1 }^{+}\end{array}$ & $\begin{array}{l}17800 \\
10800\end{array}$ \\
\hline
\end{tabular}

* Average of two different counter-selections of the donor. The reversion frequency for ile- 1 and $m e t-1$ was less than $1 \times 10^{-8}$.

Table 5. Chromosome mobilization by pAV1

\begin{tabular}{|c|c|c|c|}
\hline Donor & Recipient & $\begin{array}{l}\text { Selected donor } \\
\text { marker* }\end{array}$ & $\begin{array}{l}\text { Average no. of recombinants } \\
\text { per } 10^{6} \text { recipient cells } \dagger\end{array}$ \\
\hline C4152 & $\mathrm{C} 426$ & ${ }_{h i s-l^{+}}^{+}$ & $\begin{array}{l}25 \\
17\end{array}$ \\
\hline C4152 & C426 & $t r p-2^{+}$ & 17 \\
\hline C4152 & C476 & $\arg -10^{+}$ & $5 \cdot 5$ \\
\hline C4152 & C484 & phe-1+ ${ }^{+}$ & 134 \\
\hline C4145 & C48 & met $-1^{+}$ & 108 \\
\hline C4151 & $\mathrm{C} 48$ & $m e t-1^{+}$ & $35 \cdot 5$ \\
\hline C4152 & C459 & ala-1+ & 21 \\
\hline C4152 & C459 & cys $-3^{+}$ & 5 \\
\hline C4145 & $\mathrm{C} 48$ & ile- $1^{+}$ & 179 \\
\hline C4151 & $\mathrm{C} 48$ & ile-1+ & $54 \cdot 5$ \\
\hline
\end{tabular}

* Markers are arranged in a clockwise order from his-1 according to the map of Towner (1978). $\dagger$ Average of two different counter-selections of the donor.

\section{pAV1 transfer within EBF65/65}

When the pAV1+ strains $\mathrm{C} 4153$ and $\mathrm{C} 4152$ were crossed with other suitably marked strains of EBF65/65, the two types behaved differently with respect to the pAV1+ transconjugants obtained from these crosses. For example, when the pAV1a strain was crossed with a suitable recipient, the pAV1 ${ }^{+}$progeny were of both a- and b-types. In a sample of 65 transconjugants tested, 46 were pAV1a and 19 were pAV1b. In contrast, when the pAV1b strain was crossed with a suitable recipient strain, only pAV1b transconjugants were obtained (704 transconjugants tested). 
The plasmid pAV1, previously described by Hinchliffe \& Vivian (1980), appears to be capable of existing in two mutually exclusive states in $A$. calcoaceticus strain EBF65/65. These have been arbitrarily designated pAV1 a and pAV1b. The properties of pAV1b strains are those described for 'pAV1' by Hinchliffe \& Vivian (1980). With respect to plasmid stability, host range and incompatibility, pAVla strains behave similarly to pAV1b strains. However, whereas Hinchliffe \& Vivian (1980) found no evidence for an increase in the frequency of $\mathrm{pAV} 1 \mathrm{~b}$ transfer into $\mathrm{R} 751^{+}$recipients, the results presented here indicate that the presence of $\mathrm{R} 751$ in the recipient enhances pAVla transfer.

The main differences between the two types of pAV1+ strain are plasmid transfer and chromosome mobilization within strains of EBF65/65. It is likely that these two properties are related and therefore both result from a decrease of plasmid transfer in pAV1a strains compared with pAV1b strains. It is, however, interesting that mobilization of the nontransmissible resistance determinants for tetracycline and neomycin is apparently less influenced by the state of pAV1: pAV1a strains show about a 10-fold reduction in the frequency of mobilization, whereas the difference in sulphonamide-resistance transfer between a- and b-types is approximately 100000-fold.

The observation that pAVla strains when conjugated with other strains of EBF65/65 produced a- and b-type transconjugants is puzzling. It might imply that in the initial construction of the EBF65/65 sulphonamide-resistant transconjugants there had been selection for different plasmid types, which could only be repeated through conjugation, since a spontaneous change of pAV1 type was never detected in stability experiments. The logical extension of this argument is that pAV1 exists as pAV1a within the parent strain JC17, and only subsequent transfer to EBF65/65 will give rise to pAV1b fertility variants. Some form of recombination may be responsible for the creation of fertility variants of $\mathrm{pAV} 1$; however, this must only be effective at conjugation since the fertility variants are stable with respect to their sex factor activity. It is therefore difficult to imagine that recombination is responsible for the creation of pAV1 variants, since one might expect recombination to occur spontaneously within a population of pAV1a cells. Similarly, if deletion were responsible for the variation in fertility, one would also expect to obtain unstable variants. A more plausible explanation is that pAV1a transfers incomplete copies of itself which are derepressed for plasmid transfer; these then become b-type, since they may have lost some portion of their genetic complement responsible for their own repression. If pAV1b were a derepressed form of pAVla then one might expect to see a greater difference between pAV1a and pAV1b in their ability to mobilize the non-transmissible resistance determinants for tetracycline and neomycin. Also in this context it has been noted that the $\mathrm{R} 751^{+}$recipient strain $\mathrm{C} 4131$ does not distinguish between pAV1a and pAV1b transfer. This result may indicate that pAV1 itself is not responsible for the difference observed between a- and b-types, but that it is influenced by other factors present in the recipient.

The results presented here clearly show that pAV1b strains are good chromosome donors. It is not clear, however, from the limited data available on mapping, how pAV1 mobilizes the chromosome. Possibly it does so from a limited number of sites; for example, the data presented are consistent with two origins for transfer, both in a similar direction, located between cys-3 and ile- 1 and between arg-10 and phe-1. It is perhaps worth noting that such origins differ from those of RP4 (Towner \& Vivian, 1976 b). Alternatively, the results obtained are not inconsistent with multiple sites of origin as found by Coetzee (1978) for plasmid R772 in Proteus mirabilis.

It is hoped that physical study of these strains by agarose-gel electrophoresis will shed further light on the difference between pAVla and pAV1b strains.

It is a pleasure to record our thanks to Dr P. H. Williams for many helpful discussions during the course of this work and to Mr Tim Swift for his capable technical assistance. 


\section{REFERENCES}

Coetzee, J. N. (1978). Mobilization of the Proteus mirabilis chromosome by $\mathbf{R}$ plasmid R772. Journal of General Microbiology 108, 103-109.

Datta, N., Hedges, R. W., Shaw, E. J., Sykes, R. B. \& RichmoND, M. H. (1971). Properties of an $\mathrm{R}$ factor from Pseudomonas aeruginosa. Journal of Bacteriology 108, 1244-1249.

Hinchliffe, E. \& Vivian, A. (1980). Naturally occurring plasmids in Acinetobacter calcoaceticus: a P class $\mathrm{R}$ factor of restricted host range. Journal of General Microbiology 116, 75-80.

JobanPutRa, R. S. \& DATTA, N. (1974). Trimetho- prim resistance factors in enterobacteria from clinical specimens. Journal of Medical Microbiology 7, 169-177.

TownER, K. J. (1978). Chromosome mapping in Acinetobacter calcoaceticus. Journal of General Microbiology 104, 175--180.

TOWNER, K. J. \& VIVIAN, A. (1976a). RP4-mediated conjugation in Acinetobacter calcoaceticus. Journal of General Microbiology 93, 355-360.

Towner, K. J. \& VIVIAN, A. (1976b). RP4 fertility variants in Acinetobacter calcoaceticus. Genetical Research 28, 301-306. 